\author{
M.N. Soutsos ${ }^{1}$, G. Turu'allo ${ }^{2}$, K. Owens ${ }^{3}$, J. Kwasny ${ }^{1}$, S.J. Barnett ${ }^{4}$, P.A.M. Basheer ${ }^{1}$ \\ ${ }^{1}$ School of Planning, Architecture and Civil Engineering, Queen's University Belfast, David \\ Keir Building, Stranmillis Road, Belfast, BT9 5AG, Northern Ireland, UK \\ ${ }^{2}$ School of Engineering, University of Liverpool, Brownlow Street, Liverpool, L69 3GQ, UK \\ ${ }^{3}$ Creagh Concrete Products Ltd, Blackpark Road, Toomebridge, BT41 3SL, Northern Ireland, \\ UK
}

${ }^{4}$ School of Civil Engineering and Surveying, University of Portsmouth, Portland Building, Portland Street, Portsmouth, PO1 3AH, UK

\begin{abstract}
:
A series of laboratory tests were carried out to investigate the effect of temperature on the early-age strength development of lightweight self-compacting and vibrated concrete mixtures. These had been developed at Queen's University Belfast as part of a Technology Strategy Board funded project aimed at developing lightweight and low energy concretes. The new mixtures incorporated high volumes of pulverised fuel ash (PFA), ground granulated blast furnace slag (GGBS), and limestone powder (LSP). Activator, i.e. sodium sulphate, was used to improve the early age strength development of vibrated concrete mixtures proportioned with PFA and GGBS. For each mixture, concrete cubes were manufactured and cured under isothermal $\left(20{ }^{\circ} \mathrm{C}, 30{ }^{\circ} \mathrm{C}, 40{ }^{\circ} \mathrm{C}\right.$ and $\left.50{ }^{\circ} \mathrm{C}\right)$ as well as adiabatic conditions. The temperature rise under adiabatic curing conditions was also
\end{abstract}


measured. The resulting isothermal strength data were analysed to determine the apparent activation energies of the binders/mixtures used. The suitability of maturity methods for predicting concrete strength development of these low energy lightweight self-compacting and vibrated concrete mixtures under non-isothermal, i.e. adiabatic, curing was assessed.

Keywords: Self-compacting concrete, lightweight concrete, activator, maturity functions, activation energies, strength prediction.

\section{$1 \quad$ Introduction}

Novel low energy mixtures with self-compacting and/or lightweight properties were developed at Queen's University Belfast as part of a Technology Strategy Board funded project $^{[1-6]}$. These were intended for use by precast concrete manufacturers for products such as coffered slab units for office buildings and individually cast voussoirs of the FlexiArch ${ }^{\mathrm{TM}}$ bridge units ${ }^{[7]}$. Products with low carbon footprint are sought after for the construction of new buildings, which increases ratings of such buildings in environmental assessment methods and rating systems, e.g. BREEAM ${ }^{[8]}$. The new mixtures incorporated high volumes of pulverised fuel ash (PFA) and ground granulated blast furnace slag (GGBS). Selected vibrated mixtures, proportioned with PFA and GGBS, were activated with sodium sulphate in order to improve their early age strength development. Such mixtures are more sensitive to temperature than Portland cement mixtures. There was therefore the need to establish whether maturity functions could be used to monitor early age strength development. These could be used by the precast concrete manufacturer to (a) control the temperature of the casting bed to the required one to obtain the early age strengths needed for lifting the units, (b) identify strength variations along the depth of the element, since the heating was on the 
underside only, so as to avoid weak concrete at the top and subsequent failures during lifting, and (c) possible quality control assurance, i.e. for ensuring the strengths required are achieved, even in extreme cold weather situations, before lifting.

The need for estimating the effects of steam curing treatments on strength development led, in around 1950, to the development of maturity methods which aimed at accounting for the combined effect of time and temperature on the strength development of concrete. Carino ${ }^{[9]}$ has reviewed the historical development of maturity functions in great detail and only a summary of this is included here. It was proposed that the measured temperature history during the curing period could be used to compute a single number that would be indicative of the concrete strength. Saul ${ }^{[10]}$ called this single factor "maturity":

$$
M=\sum_{t}\left(T-T_{0}\right) \cdot \Delta t
$$

\title{
Equation 1
}

\author{
where: $\quad \mathrm{M} \quad$ is the maturity, ${ }^{\circ} \mathrm{C}$-days, \\ $\mathrm{T} \quad$ is the average temperature $\left(20^{\circ} \mathrm{C}\right.$ for standard curing) over the time \\ interval $\Delta \mathrm{t},{ }^{\circ} \mathrm{C}$, \\ $\mathrm{T}_{0} \quad$ is the datum temperature, ${ }^{\circ} \mathrm{C}$, \\ $\Delta \mathrm{t} \quad$ is the time interval, days.
}

\begin{abstract}
This equation has become known as the Nurse-Saul function and it can be used to convert a given temperature-time curing history to an equivalent age of curing at a reference temperature as follows:
\end{abstract}




$$
t_{e}=\frac{\sum\left(T-T_{0}\right)}{\left(T_{r}-T_{0}\right)} \cdot \Delta t
$$

\section{Equation 2}

where: $t_{e}$ is the equivalent age at the reference temperature, days, $\mathrm{T}_{\mathrm{r}} \quad$ is the reference temperature, ${ }^{\circ} \mathrm{C}$.

Equivalent age represents the duration of the curing period at the reference temperature that would result in the same maturity as the curing period at other temperatures. The equivalent age concept, originally introduced by Rastrup ${ }^{[11]}$, is a convenient method for using other functions besides Equation 1 to account for the combined effect of time and temperature on strength development. Equation 2 can be written as:

$$
t_{e}=\sum(\beta \cdot \Delta t)
$$

Equation 3

where:

$$
\beta=\frac{\left(T-T_{0}\right)}{\left(T_{r}-T_{0}\right)}
$$

The ratio $\beta$, which is called the "age conversion factor", is used to convert a curing interval $\Delta t$ to the equivalent curing interval at the standard reference temperature.

Functions described above are for calculating a maturity index (temperature-time factor or equivalent age) based on the temperature history of the concrete. Several functions have also been proposed to relate concrete strength to the maturity index ${ }^{[12-19]}$. The following S-shape function proposed by Carino ${ }^{[20]}$ (Equation 4) is the one recommended in the ASTM 
Standard ${ }^{[21]}$ procedure. Regression analysis is needed to provide for each curing temperature the rate constant, $\mathrm{k}_{\mathrm{T}}$, the ultimate strength, $\mathrm{S}_{\mathrm{u}}$, and the setting time, $\mathrm{t}_{0}$, of the mortar mixture. In order to calculate the apparent activation energy, $E_{a}$, the ASTM Standard's ${ }^{[21]}$ recommendation is to plot $\ln \left(\mathrm{k}_{\mathrm{T}}\right)$ against $1 / \mathrm{T}_{\mathrm{abs}}$ (given in $1 /$ Kelvin), where $\mathrm{T}_{\mathrm{abs}}$ is the absolute curing temperature. The slope of the trend line is equal to -Q and the activation energy for the mixture will be equal to $\mathrm{Q} \cdot \mathrm{R}$, where $\mathrm{R}$ is the universal gas constant equal to $8.31 \mathrm{~J} / \mathrm{K} \cdot \mathrm{mol}$.

$$
S=\frac{S_{u} \cdot k_{T} \cdot\left(t-t_{0}\right)}{1+k_{T} \cdot\left(t-t_{0}\right)}
$$

\section{Equation 4}

where: S strength at age t, MPa,

$\mathrm{S}_{\mathrm{u}} \quad$ ultimate mortar strength at temperature $\mathrm{T}, \mathrm{MPa}$,

$\mathrm{k}_{\mathrm{T}}$ rate constant at temperature $\mathrm{T}, 1 / \mathrm{day}$,

t test age, days,

$\mathrm{t}_{0} \quad$ age at which mortar strength development is initiated at temperature $\mathrm{T}$, days.

The equivalent age is then related to $\mathrm{Q}$ based on the following equation:

$$
t_{e}=\sum e^{-Q \cdot\left(\frac{1}{T_{a}}-\frac{1}{T_{s}}\right)} \cdot \Delta t
$$

Equation 5

where: $\mathrm{T}_{\mathrm{a}} \quad$ average temperature of concrete during time interval $\Delta \mathrm{t}, \mathrm{K}$,

$\mathrm{T}_{\mathrm{s}} \quad$ specified reference temperature, $\mathrm{K}$.

Apparent activation energies can be determined using "equivalent" mortar specimens, as described in ASTM Standard C1074-98 ${ }^{[21]}$ and the results applied to the concrete under 
investigation. Values for activation energies reported in the literature ${ }^{[20]}$ range from 33,500 $\mathrm{J} / \mathrm{gmol}$ to $63,600 \mathrm{~J} / \mathrm{gmol}$, see Table 1 . All of these concrete mixtures had normal weight aggregate and not lightweight aggregate. According to ASTM Standard C1074-98 ${ }^{[21]}$, tests can be performed on mortar specimens and the results applied to the concrete under investigation. The equivalent mortars need to have the same water-binder ratios and superplasticiser dosages as the concretes. The sand/binder ratios also need to be equal to the coarse/binder ratios of the concretes. These requirements are to ensure that the strength development of the mortar specimens is similar to that of the corresponding concrete mixtures. Unfortunately, equivalent mortar specimens cannot be used for lightweight concretes as their densities will be much different and this will affect the strength development. Activation energies need therefore be determined on concrete cube specimens. The volume of concrete is considerable in this case and it is not surprising that (a) the equivalent mortar method is favoured, and (b) no data for activation energies has been found in the literature for lightweight aggregate concretes.

Therefore, the aim of this project was to determine activation energies for lightweight selfcompacting and vibrated concretes and to determine the suitability of maturity methods for predicting concrete strength development under non-isothermal (adiabatic) curing.

\section{$2 \quad$ Material and Experimental Procedures}

Eight concrete mixtures were prepared according to mixture proportions derived at Queen's University Belfast (QUB $)^{[1-3]}$ in close collaboration with the industry and these are shown in Table 2. For each concrete mixture, two batches of concrete (90 litres each) were manufactured. 


\subsection{Materials}

A single batch of Portland cement (PC) CEM I 42.5N was used throughout. When required, PC was partially replaced with pulverised fuel ash (PFA), ground granulated blast furnace slag (GGBS) or limestone powder (LSP). The fine aggregate was a very fine sand where $69 \%$ of the particles passed through the $600 \mu \mathrm{m}$ sieve. The coarse aggregate was all but for one mixture sintered fly ash lightweight aggregate (Lytag), size 4 to $14 \mathrm{~mm}$. One mixture used normal weight aggregate in the form of granite with a maximum aggregate size of $20 \mathrm{~mm}$. All aggregates were air-dried before use. The moisture content was determined by oven drying a sample and then allowance was made for absorption when calculating batch weights for mixing. Two superplasticisers were used: SP1, a superplasticising and accelerating concrete admixture based on polycarboxylate polymers and SP2, a third generation synthetic polycarboxylate polymer-based superplasticiser. The specific gravity of SP1 was 1.08 and that of SP2 was 1.10 , whilst their solid contents were equal to $40 \%$ and $35 \%$, respectively. A sodium sulphate activator was used for some of the mixtures.

\subsection{Mixing, Casting, Curing and Testing of Concrete Specimens}

Materials for concrete mixtures were weighed and placed in a $0.1 \mathrm{~m}^{3}$ capacity horizontal pan mixer. For vibrated concrete mixtures the coarse aggregate and sand were first placed in the mixer with half the water, mixed for 30 second and left to stand for 10 minutes. Cement and other powders, i.e. PFA or GGBS, were then added followed by the remaining water. In the case of the activated mixtures the remaining water contained the dissolved sodium sulphate. These were then mixed for 2 to 3 minutes before adding the superplasticiser. The specimens were compacted in two layers and subsequently wrapped in polythene sheet and transferred 
to curing tanks/environmental chamber. For self-compacting mixtures the coarse aggregate and sand were first placed in the mixer with $2 / 3$ of the water and mixed for 2 minutes. GGBS or LSP were then added and mixing continued for another 1 minute. Cement was subsequently added and mixing continued for a further 1 minute before adding the remaining water and superplasticiser. The concrete was mixed for a further 2 minutes.

The $100 \mathrm{~mm}$ size concrete cubes were manufactured and water cured under isothermal conditions $\left(20^{\circ} \mathrm{C}, 30^{\circ} \mathrm{C}, 40^{\circ} \mathrm{C}\right.$ and $\left.50{ }^{\circ} \mathrm{C}\right)$. Another set of $100 \mathrm{~mm}$ size cubes was cast for water curing under adiabatic conditions. In addition, an "adiabatic" concrete spacemen was cast in a plywood $240 \mathrm{~mm}$ size cube mould lined with $20 \mathrm{~mm}$ expanded polystyrene to further insulate it and heavy duty polythene to prevent moisture loss. This "adiabatic" specimen (240 mm size cube) was then placed in an environmental chamber which was set up in the way described below so that it would follow the adiabatic temperature history of the concrete.

For each curing regime, 3 replicate cubes were tested at the following ages: 3 hours, 6 hours, 12 hours, 24 hours, 2 days, 4 days, 7 days, 14 days, and 28 days.

\subsection{Adiabatic Temperature Measurements}

The adiabatic temperature rise due to hydration of cement is the temperature rise which will occur if fresh concrete is stored in a perfectly insulated environment, i.e. one from which no heat loss can occur. To achieve this state it is necessary to either heavily insulate the concrete or alternatively to ensure that the environment in which the concrete is stored is at the same 
or nearly the same temperature as the concrete. The latter approach was adopted in this research programme, see Figure 1.

Following test set-up was used ${ }^{[22]}$. Two copper/constantan thermocouples were inserted, through a hole in the top of the mould, in the "adiabatic" concrete specimen $(240 \mathrm{~mm}$ size samples). Two more copper/constantan thermocouples were used to monitor the temperature of the curing tank. The thermocouples were all connected to a computer which not only recorded the temperatures but also was set to activate the cabinet when the temperature difference between the curing tank and the concrete was $1{ }^{\circ} \mathrm{C}$. It can be assumed, based on the fact that there was no temperature drop after the maximum had been reached, that there was only very little heat loss and no adjustment was needed for the results.

\section{$3 \quad$ Results and Discussion}

\subsection{Activation Energies}

The concrete compressive strength test results for all 4 curing temperatures, i.e. $20{ }^{\circ} \mathrm{C}, 30{ }^{\circ} \mathrm{C}$, $40{ }^{\circ} \mathrm{C}$ and $50{ }^{\circ} \mathrm{C}$, were plotted as shown in Figure 2. The parameters $\mathrm{S}_{\mathrm{u}}, \mathrm{t}_{0}$ and $\mathrm{k}_{\mathrm{T}}$ in Equation 4 were obtained by regression analysis using a commercially available statistical analysis software package called SigmaPlot ${ }^{[23]}$. Table 3 shows these three parameters for each concrete mixture and for each curing temperature.

The datum temperature of each mixture was not estimated by plotting the $\mathrm{k}_{\mathrm{T}}$ values against the curing temperature. This requires a trend line to be fitted and the datum temperature deduced from its intercept at the x-axis. However, in this study the datum temperature determined with this procedure has been shown not to be reliable and, therefore, the value of $-11{ }^{\circ} \mathrm{C}$ was used instead for strength predictions. This is the average of what has been 
recommended in literature, i.e. usually taken to be between $-10{ }^{\circ} \mathrm{C}$ and $-12{ }^{\circ} \mathrm{C}$ Plowman $^{[9,10,12]}$.

In order to calculate the apparent activation energy, $E_{a}$, the ASTM Standard's recommendation is to plot $\ln \left(\mathrm{k}_{\mathrm{T}}\right)$ against $1 / \mathrm{T}_{\mathrm{abs}}(1 /$ Kelvin $)$, where $\mathrm{T}_{\mathrm{abs}}$ is the absolute curing temperature, see Figure 3. The slope of the trend line is equal to -Q and the activation energy for the mixture will be equal to $\mathrm{Q} \cdot \mathrm{R}$, where $\mathrm{R}$ is the universal gas constant equal to 8.31 J/Kmol. Activation energies determined are shown in Table 4.

Activation energy values were found to vary approximately from 20 to $42 \mathrm{~kJ} / \mathrm{mol}$. The higher the activation energy the higher was the effect of temperature on the strength development of the concrete mixtures.

Neat Portland cement mixtures, i.e. CEM I, are expected to be at the lower end of the range of activation energies, i.e. around 20 to $27 \mathrm{~kJ} / \mathrm{mol}$. Values found in the literature, see Table 1, increase confidence in these values. Higher values reported seem to be associated with high strength concrete mixtures with low water-cement ratios. Although it is generally accepted $^{[24]}$ that activation energies may not be affected by the water-cement ratio, there is information in the literature implying that this may only be true for normal strength concretes $^{[25]}$.

Activation energies for PFA mixtures quoted in the literature (Table 1) vary a lot, i.e. from 20 to $37 \mathrm{~kJ} / \mathrm{mol}$. The higher values appear to be from research carried out in USA and may be associated with high calcium content of PFA which is not available in the UK. 
Activation energies for GGBS mixtures have been reported to be at the high end of the range, i.e. from 40 to $60 \mathrm{~kJ} / \mathrm{mol}$ (Table 1). It is worth noting that the values determined in this programme of work are at the lower end of the range reported in the literature despite one of the two GGBS mixtures having a chemical activator. The activation energy of the activated GGBS mixture was actually found to be lower than the one without it.

\subsection{Strength Prediction of Adiabatically Cured Concretes}

The strength development of concretes under adiabatic curing regimes is challenging to predict. The temperature histories, see Figure 4, are higher than those that are normally recorded in in-situ construction of structural elements. The temperature rise also occurs much earlier than concrete cast in-situ. Nonetheless they offer a way of calibrating the accuracy of strength predictions made with previously determined activation energies.

The neat PC lightweight concrete mixture, i.e. LW-PC Control, reaches a peak temperature of around $80{ }^{\circ} \mathrm{C}$ (Figure 4). This mixture has the highest cement content from the concretes that are not self-compacting concretes. Use of PFA (LW-PFA) significantly reduces the peak temperature of the concrete by more than $20^{\circ} \mathrm{C}$. It is interesting to note the effect of the activator (LW-PFA Activated), i.e. it accelerates the reaction so that the peak temperature occurs earlier but does not increase the peak temperature. Use of GGBS (LW-GGBS) reduces the peak temperature less than PFA, i.e. by only $10{ }^{\circ} \mathrm{C}$. It is worth noting that the use of the activator with this binder (LW-GGBS Activated) appears to on one hand accelerate the reaction but on the other hand it reduces the peak temperature.

The self-compacting concrete with $100 \%$ PC (NWSCC-PC Control) has a $10{ }^{\circ} \mathrm{C}$ temperature difference from the vibrated one (LW-PC Control). A possible explanation for this difference 
could be the different aggregate used. The self-compacting concrete with LSP (LWSCCLSP) has approximately the same peak rise as the vibrated concrete with neat PC (LW-PC Control) despite having lower cement content and lower water-cement ratio. The selfcompacting concrete with GGBS (LWSCC-GGBS) has a total binder content of approximately $600 \mathrm{~kg} / \mathrm{m}^{3}$ and it therefore reaches a peak temperature of $92{ }^{\circ} \mathrm{C}$.

Figure 5 depicts the adiabatic compressive strength measured on the $100 \mathrm{~mm}$ size concrete specimens. The strength development obtained at $20{ }^{\circ} \mathrm{C}$, i.e. normal curing, the adiabatic temperature history and the activation energies previously obtained were used to estimate the strength development of adiabatically cured concrete mixtures and shown as "Predicted" curve in Figure 5. The equivalent age, $t_{e}$, at time, $t$, was first calculated using Equation 5 which requires the value of activation energy $E=Q / R$ for the specific concrete (Table 4). The specified reference temperature, $\mathrm{T}_{\mathrm{s}}$, of $293 \mathrm{~K}\left(20^{\circ} \mathrm{C}\right)$ was used in Equation 5. The value of equivalent age obtained, $t_{e}$, was then substituted for $t$ in Equation 4 with constants $S_{u}, k_{T}$ and $t_{0}$ as previously determined for the strength data obtained for similar concretes cured at $20{ }^{\circ} \mathrm{C}$ (see Table 3). The strengths obtained, i.e. predicted, were then plotted versus $\mathrm{t}$ as shown in Figure 5.

The acceleration of the strength development resulting from higher early age curing temperatures is predicted well thus increasing confidence in the values of activation energies previously determined. The cross-over effect (i.e. at the same value of low maturity, a high curing temperature results in greater strength than a low curing temperature, and conversely at later maturities, result in lower strength ${ }^{[26]}$ ) appears from an early age for some of the mixtures tested, especially the ones with GGBS. The cross-over effect results in an overestimate of the ultimate strengths as it does not consider the detrimental effect of early age 
curing temperatures. On the other hand, the 28-day strength prediction for the lightweight vibrated PFA concrete (LW-PFA) and the activated one (LW-PFA Activated) is underestimated. The reason for this is that PFA contributes to the strength at later ages and testing ages of 56 and 91 days are needed to determine accurately the strength versus age relationship.

\section{Conclusions}

There does not seem to have been any other study that has evaluated the use of maturity functions for lightweight aggregate concretes. Conclusions from this work are:

- The early age strength development of lightweight concretes can be predicted relatively accurately from the activation energies determined in this research project.

- Activation energies for lightweight aggregate concretes appear to be similar to those of normal aggregate concrete with similar binders.

- Equivalent ages can be determined based on the strength requirements of precast concrete factories. These can then be used to determine the curing temperature required, as well as its duration, for these strengths to be achieved.

- Measurement of temperature history can be used together with maturity functions to monitor the strength development of factory cast specimens if these are to be air cured, i.e. variable temperature history. 
- Measurement of temperature history, together with maturity functions, can also be used for the estimation of in-place strength based on strength development data obtained under standard laboratory conditions

Improved early age strengths resulting from high early age curing temperatures can also be exploited in fast track construction. However, to achieve this then (a) the expected in-situ temperature history will have to be modelled using finite element analysis software - heat of hydration values, which can be obtained from adiabatic tests, will be needed as inputs, and, (b) the in-situ strength development will have to be predicted using maturity functions.

\section{Acknowledgements}

The work reported here was part of the Technology Strategy Board funded research project (Ref. No.: APPS2B/Q1579L) at Queen's University Belfast. The majority of the work described here was carried out in the University of Liverpool as a subcontract. The authors are grateful to the School of Engineering, the University of Liverpool for the facilities provided and to the Technology Strategy Board for the financial support.

\section{REFERENCES}

1. Owens KJ, Bai Y, Kwasny J, Basheer PAM, Cleland D, Taylor S, Sonebi M. Development of structural lightweight, chemical activated blended cementitious concretes. In: Nualláin NN, Walsh D, West R, Cannon E, Caprani C, McCabe B, editors. Proceedings of 2010 BCRI conference, Cork, Ireland, 2-3 Sep 2010; 2010, p. 645-652.

2. Kwasny J, Sonebi M, Taylor SE, Bai Y, Owens K, Basheer PAM, Cleland DJ. Influence of the type of coarse lightweight aggregate on fresh properties of Semi-Lightweight SelfConsolidating Concrete. In: Khayat KH, Feys D, editors. Proceedings of 6th International 
RILEM Symposium on Self-Compacting Concrete, Montreal, Canada, 26-29 Sep 2010; 2010;2(CD-ROM), p. 233-242.

3. Kwasny J, Sonebi M, Taylor SE, Bai Y, Owens K, Doherty W. Influence of the Type of Coarse Lightweight Aggregate on Properties of Semi-Lightweight Self-Consolidating Concrete. J Mater Civ Eng 2012;24(12):1474-1483.

4. Kwasny J, Sonebi M, Taylor SE, Bai Y, Basheer PAM, Owens K, Cleland DJ. The influence of different viscosity-modifying admixtures on the fresh properties of superplasticised cement-based grouts. In: Wallevik OH, Kubens S, Oesterheld S, editors. Proceedings of 3rd RILEM International Symposium on Rheology of Cement Suspensions Like Fresh Concrete (Rheo Iceland 2009), Reykjavik, Iceland, 19-21 Aug 2009, RILEM Publications S.A.R.L., PRO 68, 2009, p. 208-218.

5. Owens K, Bai Y, Cleland D, Basheer PAM, Kwasny J, Sonebi M, Taylor S, Gupta A. Activation of High Volume Fly Ash Pastes using Chemical Activators. In: Zachar J, Claisse P, Naik TR, Ganjian E, editors. Proceedings of Second International Conference on Sustainable Construction Materials and Technologies, Ancona, Italy, 28-30 Jun 2010, Vol. 3, 2010, p. 1759-1770.

6. Mokhtar MR, Sun T, Grattan KTV, Owens K, Kwasny J, Taylor SE, Basheer PAM, Cleland D, Bai Y, Sonebi M, Davis G, Gupta A, Hogg I, Bell B, Doherty W, McKeague S, Moore D, Greeves K. Fiber-optic Strain Sensor with Temperature Compensation for Arch Bridge Condition Monitoring. IEEE Sens J 2012;12(5):1470-1476.

7. Long AE. Concrete arch and method of manufacture. United States patent US 7204058 B2; 17 April 2007.

8. BREEAM. The world's foremost environmental assessment method and rating system for buildings. BRE 2011, (accessed Nov 2012 at http://www.breeam.org).

9. Carino NJ. The Maturity Method. In: Malhotra VM, Carino NJ, editors. Handbook on Nondestructive Testing of Concrete. 2nd ed. CRC Press; 2004, p. 5.1-5.47.

10. Saul AGA. Principles underlying the steam curing of concrete at atmospheric pressure. Mag Concrete Res 1951;2(6):127-140.

11. Rastrup E. Heat of hydration in concrete. Mag Concrete Res 1954;6(17):79-92.

12. Plowman JM. Maturity and the strength of concrete. Mag Concrete Res 1956;8(22):13.

13. Nykanen A. Hardening of concrete at different temperatures, especially below the freezing point. In: Proceeding of RILEM Symposium On Winter Concreting, Session BII, Copenhagen: Danish Institute for Building Research; 1956. 
14. Bernhardt CJ. Hardening of concrete at different temperatures. In: Proceeding of RILEM Symposium On Winter Concreting, Session BII, Copenhagen: Danish Institute for Building Research; 1956.

15. Carino NJ. Temperature effects on strength-maturity relation of mortar. NBSIR 81-244, Gaithersburg, MD, USA: National Bureau of Standards; 1981.

16. Goral ML. Empirical time-strength relations of concrete. J Am Conc Inst 1956;53(8): $215-224$.

17. Chin FK. Relation between strength and maturity of concrete. J Am Conc Inst 1971;68(3):196-203.

18. Lew HS, Reichard TW. Prediction of strength of concrete from maturity. In: Malhotra VM, editor. ACI SP-56 Accelerated Strength Testing, Farmington Hills, MI, USA: American Concrete Institute; 1978, p. 229-248.

19. Freiesleben HP, Pedersen EJ. Curing of concrete structures. CEB Information Bulletin 166; May 1985.

20. Carino NJ, Tank RC. Maturity Functions for Concretes Made with Various Cements and Admixtures. ACI Mater J 1992;89(2):188-196.

21. ASTM C1074-98 Standard practice for estimating concrete strength by the maturity method. In: Annual book of ASTM Standards, Vol. 04.02: Concrete and Aggregates, West Conshohocken, Pennsylvania, USA: ASTM International; 1999, p. 540-547.

22. Barnett SJ, Soutsos MN, Bungey JH, Millard, SG. Fast-Track Construction with Slag Cement Concrete: Adiabatic Strength Development and Strength Prediction. ACI Mater J, 2007 104(4): 388-396.

23. SigmaPlot version 11.0, Systat Software Inc., San Jose California USA, www.sigmaplot.com.

24. Nisbet EG, Maitland ST. Mass concrete sections and the maturity concept. Can J Civ Eng $1976 ; 3: 47-57$.

25. Hudson SB, Steele GW. Prediction of potential strength of concrete from early ages. Higway Res Rec 1971;370:25-36.

26. McIntosh, JD. The effects of low-temperature curing on the compressive strength of concrete. In: Proceedings of RILEM Symposium on Winter Concreting, Session BII, Copenhagen: Danish Institute for Building Research; 1956.

27. Hatzitheodorou A. Insitu Strength Development of Concretes with Supplementary Cementitious Materials. PhD Thesis, The University of Liverpool; 2007, p. 531. 
28. BS EN 206-1:2000 Concrete. Specification, performance, production and conformity. London, UK: British Standards Institution; 2000. 
Table 1: Activation Energy Values found in the literature

\begin{tabular}{|c|c|c|c|}
\hline Concrete Mixture Identifier & Source & $\mathbf{w} / \mathbf{b}$ & $\begin{array}{c}\text { Activation Energy } \\
(\mathrm{kJ} / \mathrm{mol})\end{array}$ \\
\hline CEM I (C25/30*) & Hatzitheodorou $^{[27]}$ & 0.66 & 22.851 and 37.382 \\
\hline CEM I (C40/50*) & Hatzitheodorou $^{[27]}$ & 0.46 & 18.063 and 29.698 \\
\hline Type I Cement & Carino \& Tank ${ }^{[20]}$ & 0.60 & 48.000 \\
\hline Type I Cement & Carino \& Tank ${ }^{[20]}$ & 0.45 & 61.100 \\
\hline $\begin{array}{l}\text { General for Type I Cement } \\
\text { (without admixtures) }\end{array}$ & ASTM C1074-98 ${ }^{[21]}$ & - & $40.000-45.000$ \\
\hline CEM I + 30\% PFA (C25/30*) & Hatzitheodorou $^{[27]}$ & 0.53 & 19.440 and 22.539 \\
\hline $\mathrm{CEM} \mathrm{I}+30 \%$ PFA $(\mathrm{C} 40 / 50 *)$ & Hatzitheodorou $^{[27]}$ & 0.35 & 27.309 and 34.506 \\
\hline Type I Cement + 20\% PFA & Carino \& Tank ${ }^{[20]}$ & 0.60 & 36.600 \\
\hline Type I Cement $+20 \%$ PFA & Carino \& Tank ${ }^{[20]}$ & 0.45 & 33.100 \\
\hline CEM I + 30\% GGBS (C25/30*) & Hatzitheodorou $^{[27]}$ & 0.65 & 53.265 and 59.600 \\
\hline CEM I + 30\% GGBS (C40/50*) & Hatzitheodorou $^{[27]}$ & 0.46 & 41.296 and 41.606 \\
\hline Type I Cement $+50 \%$ GGBS & Carino \& Tank ${ }^{[20]}$ & 0.60 & 51.300 \\
\hline Type I Cement $+50 \%$ GGBS & Carino \& Tank ${ }^{[20]}$ & 0.45 & 42.700 \\
\hline CEM I + 10\% Microsilica (C70/85*) & Hatzitheodorou $^{[27]}$ & 0.25 & 38.999 and 50.997 \\
\hline
\end{tabular}

* - Concrete compressive strength class according to BS EN 206-1:2000 $0^{[28]}$ 
Table 2: Concrete Mixture Proportions

\begin{tabular}{|c|c|c|c|c|c|c|c|c|}
\hline $\begin{array}{l}\text { Concrete } \\
\text { Mixture } \\
\text { Identifier }\end{array}$ & $\begin{array}{ll}0 \\
0\end{array}$ & $\frac{4}{a}$ & 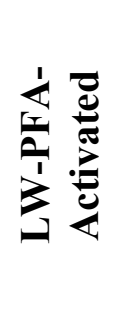 & $\begin{array}{c}\infty \\
0 \\
0 \\
1 \\
1 \\
1\end{array}$ & 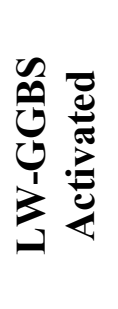 & 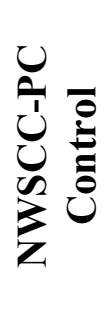 & 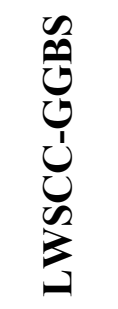 & Uี \\
\hline $\begin{array}{c}\text { Mixture } \\
\text { Constituents }\end{array}$ & \multicolumn{8}{|c|}{$\begin{array}{c}\text { Quantity } \\
\mathrm{kg} / \mathrm{m}^{3}\end{array}$} \\
\hline CEM I & 450 & 225 & 225 & 225 & 225 & 460 & 424 & 419 \\
\hline PFA & - & 154 & 154 & - & - & - & - & - \\
\hline GGBS & - & - & - & 211 & 211 & - & 181.5 & - \\
\hline LSP & - & - & - & - & - & - & - & 180 \\
\hline $\begin{array}{c}\text { Lytag } \\
4-14 \mathrm{~mm}\end{array}$ & 561 & 561 & 561 & 561 & 561 & - & 351 & 351 \\
\hline Sand & 787 & 787 & 787 & 787 & 787 & 818 & 818 & 818 \\
\hline Granite & - & - & - & - & - & 896 & - & - \\
\hline $\mathrm{Na}_{2} \mathrm{SO}_{4}$ & - & - & 15.15 & - & 17.43 & - & - & - \\
\hline SP1 & 2.25 & 1.89 & 1.89 & 2.18 & 2.18 & - & - & - \\
\hline SP2 & - & - & - & - & - & 1.611 & 3.3 & 3.3 \\
\hline Free water & 189 & 159 & 159 & 183 & 183 & 208 & 210 & 208 \\
\hline Free $w / b$ & 0.42 & 0.42 & 0.42 & 0.42 & 0.42 & 0.45 & 0.35 & 0.35 \\
\hline
\end{tabular}


Table 3: Regression Parameters obtained from Equation 4

\begin{tabular}{|c|c|c|c|c|c|}
\hline \multirow{2}{*}{$\begin{array}{l}\text { Concrete Mixture } \\
\text { Identifier }\end{array}$} & \multirow{2}{*}{$\begin{array}{c}\text { Curing Temp. } \\
\left({ }^{\circ} \mathrm{C}\right)\end{array}$} & \multicolumn{4}{|c|}{ Regression Parameters } \\
\hline & & $\mathrm{S}_{\mathrm{u}}(\mathrm{MPa})$ & $\mathrm{k}_{\mathrm{T}}$ (1/day) & $\mathrm{t}_{0}$ (day) & $\mathrm{R}^{2}$ \\
\hline \multirow{4}{*}{ LW-PC Control } & 20 & 45.1342 & 1.0747 & 0.2200 & 0.9978 \\
\hline & 30 & 46.5641 & 1.4850 & 0.1820 & 0.9973 \\
\hline & 40 & 43.6659 & 2.3291 & 0.1143 & 0.9919 \\
\hline & 50 & 42.8027 & 1.9324 & 0.0618 & 0.9748 \\
\hline \multirow{4}{*}{ LW-PFA } & 20 & 36.0680 & 0.3633 & 0.2757 & 0.9932 \\
\hline & 30 & 37.2000 & 0.4821 & 0.1419 & 0.9895 \\
\hline & 40 & 42.6950 & 0.4868 & 0.0303 & 0.9875 \\
\hline & 50 & 40.2881 & 1.0374 & 0.0823 & 0.9904 \\
\hline \multirow{4}{*}{ LW-PFA Activated } & 20 & 32.8476 & 0.6652 & 0.1940 & 0.9756 \\
\hline & 30 & 37.9515 & 0.6812 & 0.0206 & 0.9585 \\
\hline & 40 & 34.7283 & 1.2395 & 0.0690 & 0.9865 \\
\hline & 50 & 32.0804 & 1.6305 & 0.0000 & 0.9649 \\
\hline \multirow{4}{*}{ LW-GGBS } & 20 & 47.9345 & 0.2419 & 0.3620 & 0.9954 \\
\hline & 30 & 50.2172 & 0.4127 & 0.2245 & 0.9990 \\
\hline & 40 & 48.0835 & 0.7337 & 0.1707 & 0.9910 \\
\hline & 50 & 43.2951 & 1.1346 & 0.1199 & 0.9959 \\
\hline \multirow{4}{*}{ LW-GGBS Activated } & 20 & 40.0872 & 0.5518 & 0.2608 & 0.9969 \\
\hline & 30 & 40.5744 & 0.8712 & 0.1983 & 0.9977 \\
\hline & 40 & 39.9613 & 1.0074 & 0.0202 & 0.9895 \\
\hline & 50 & 33.3558 & 2.1255 & 0.0000 & 0.9162 \\
\hline \multirow{4}{*}{ NWSCC-PC Control } & 20 & 63.3790 & 0.5950 & 0.3980 & 0.9963 \\
\hline & 30 & 60.0823 & 0.8715 & 0.1982 & 0.9936 \\
\hline & 40 & 57.9857 & 1.0004 & 0.0463 & 0.9938 \\
\hline & 50 & 54.8870 & 1.4751 & 0.0646 & 0.9785 \\
\hline \multirow{4}{*}{ LWSCC-GGBS } & 20 & 56.3194 & 0.6146 & 0.3590 & 0.9968 \\
\hline & 30 & 54.8325 & 1.0666 & 0.2331 & 0.9990 \\
\hline & 40 & 52.5678 & 1.6869 & 0.1954 & 0.9971 \\
\hline & 50 & 51.6407 & 2.5280 & 0.1170 & 0.9980 \\
\hline \multirow{4}{*}{ LWSCC-LSP } & 20 & 45.5570 & 0.8381 & 0.3491 & 0.9947 \\
\hline & 30 & 42.4575 & 1.4086 & 0.1832 & 0.9952 \\
\hline & 40 & 40.6134 & 1.6288 & 0.1033 & 0.9783 \\
\hline & 50 & 38.6104 & 1.8124 & 0.0385 & 0.9828 \\
\hline
\end{tabular}


Table 4: Activation Energy Values obtained using the ASTM Method ${ }^{[21]}$

\begin{tabular}{|c|c|}
\hline $\begin{array}{c}\text { Concrete Mixture } \\
\text { Identifier }\end{array}$ & $\begin{array}{c}\text { Activation Energy } \\
\text { (kJ/mol) }\end{array}$ \\
\hline LW-PC Control & 17.636 \\
\hline LW-PFA & 24.591 \\
\hline LW-PFA Activated & 25.724 \\
\hline LW-GGBS & 41.032 \\
\hline LW-GGBS Activated & 32.811 \\
\hline NWSCC-PC Control & 22.501 \\
\hline LWSCC-GGBS & 37.041 \\
\hline LWSCC-LSP & 19.549 \\
\hline
\end{tabular}




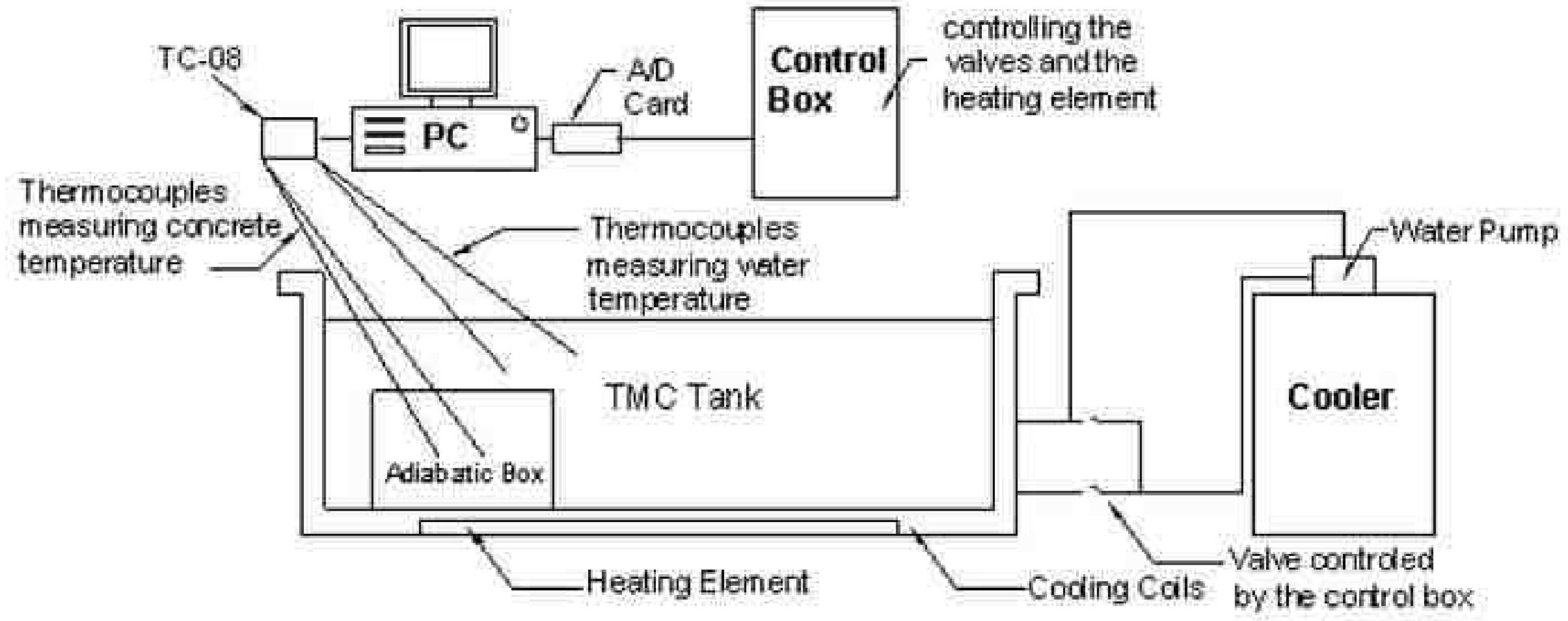




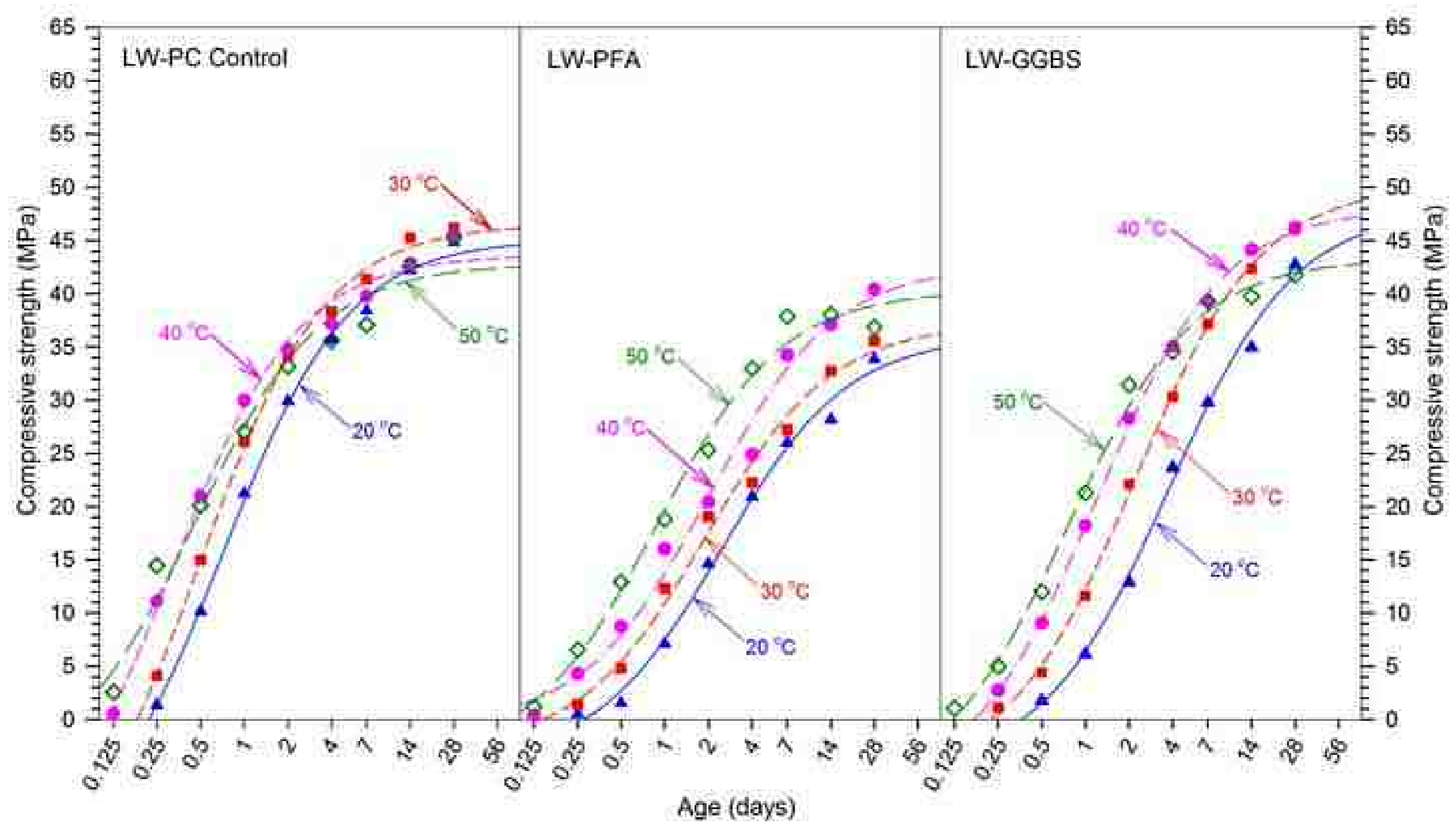




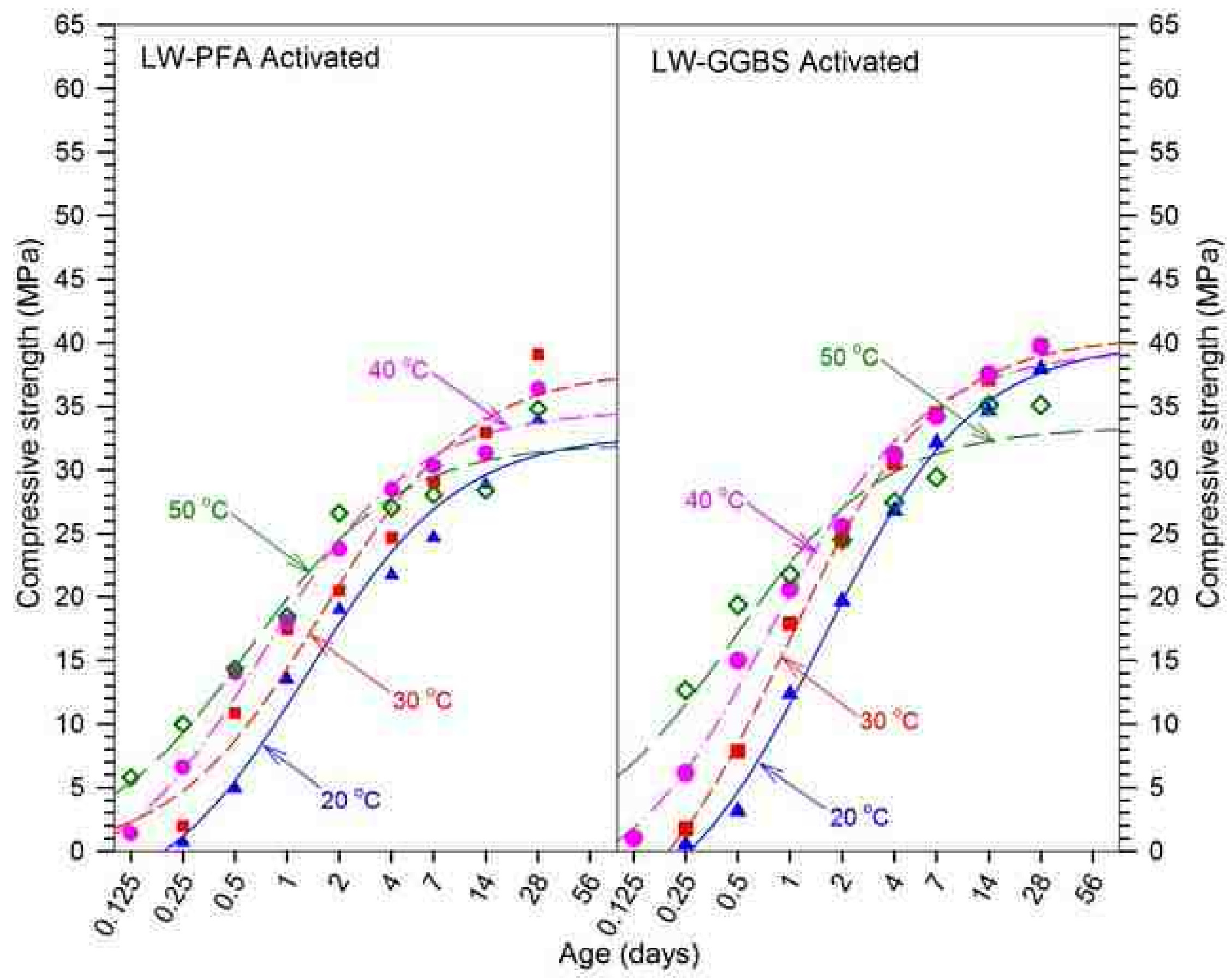




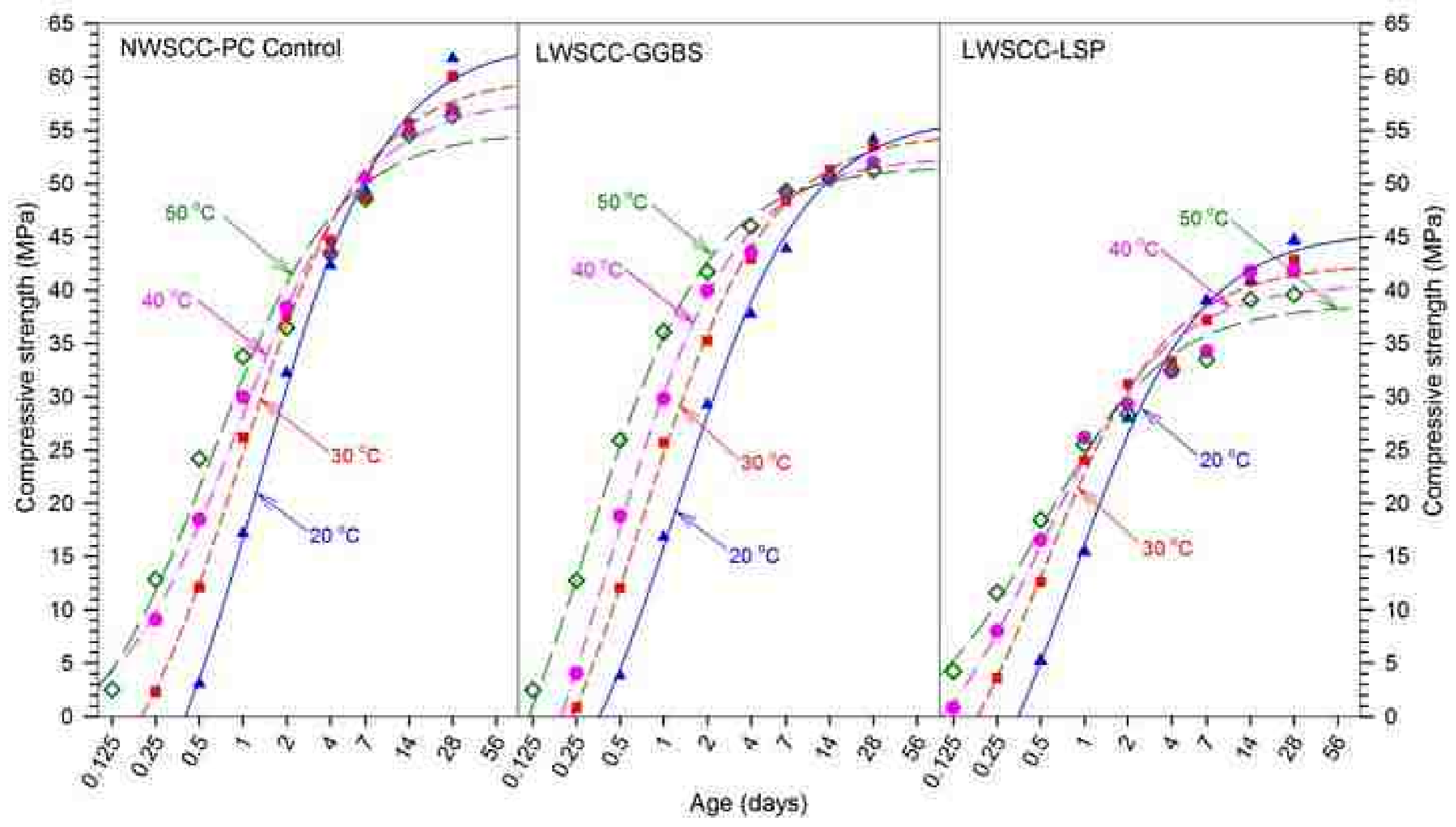




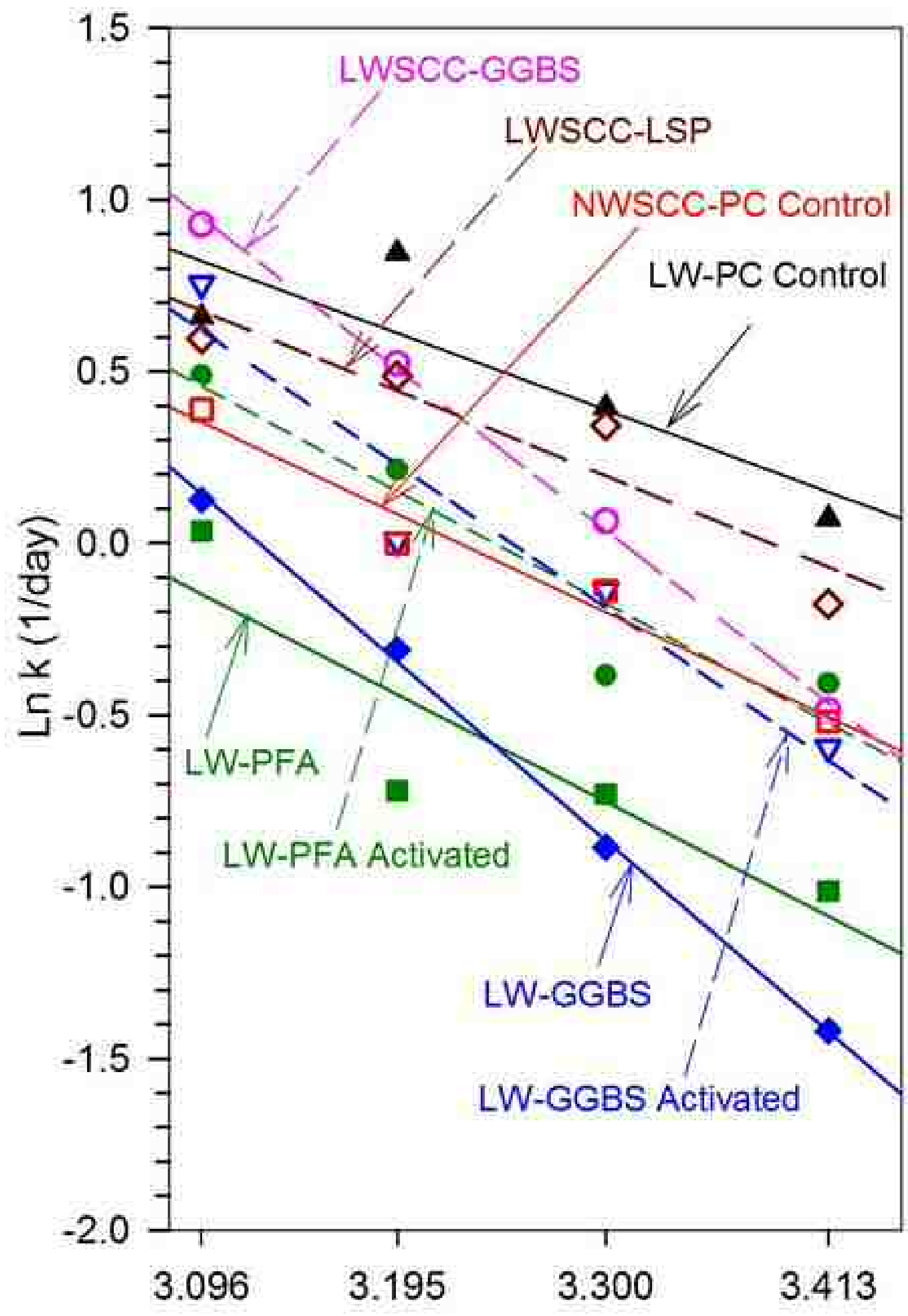

1/Absolute Temperature $\left(\times 10^{-3}{ }^{\circ} \mathrm{K}\right)$ 


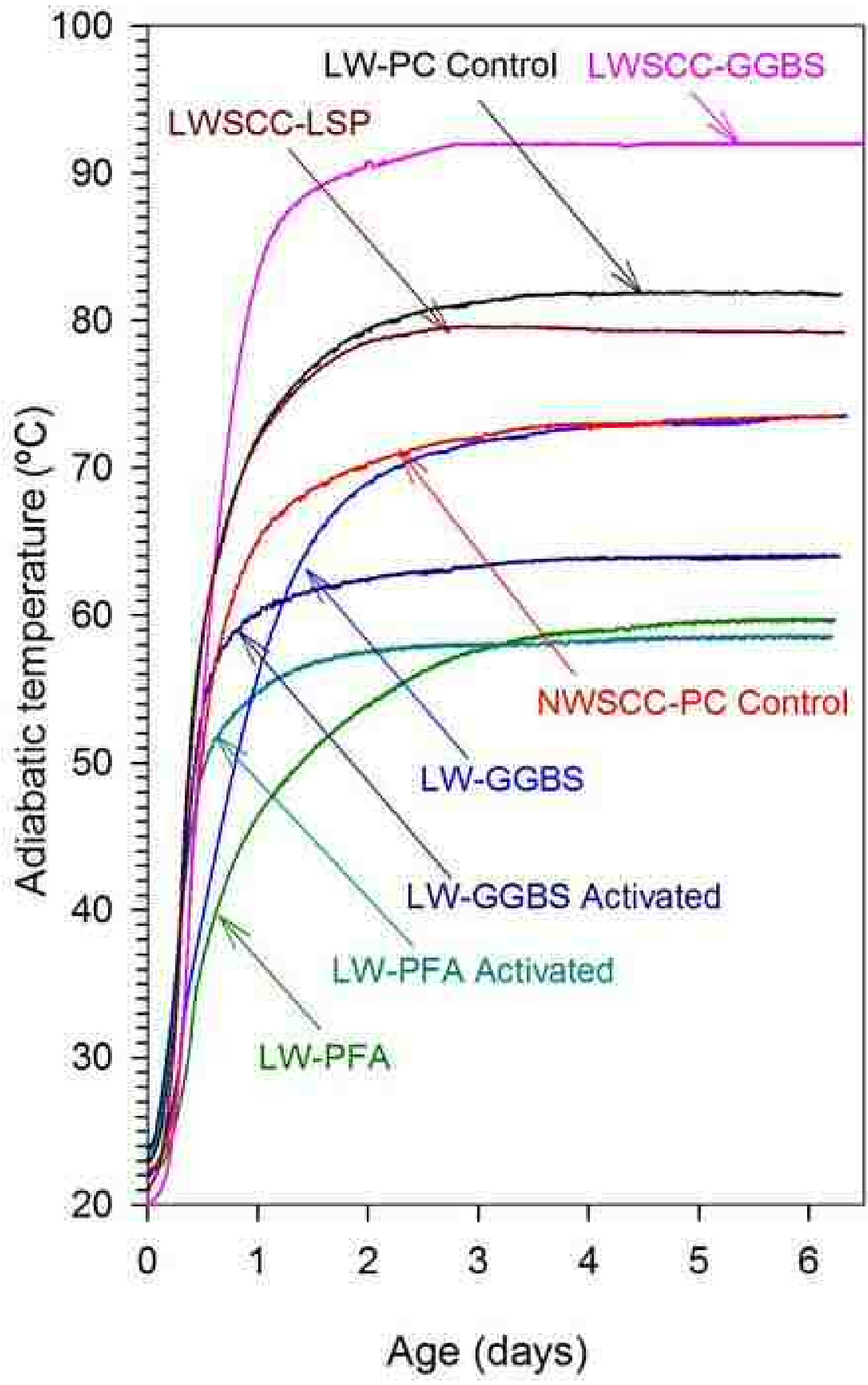




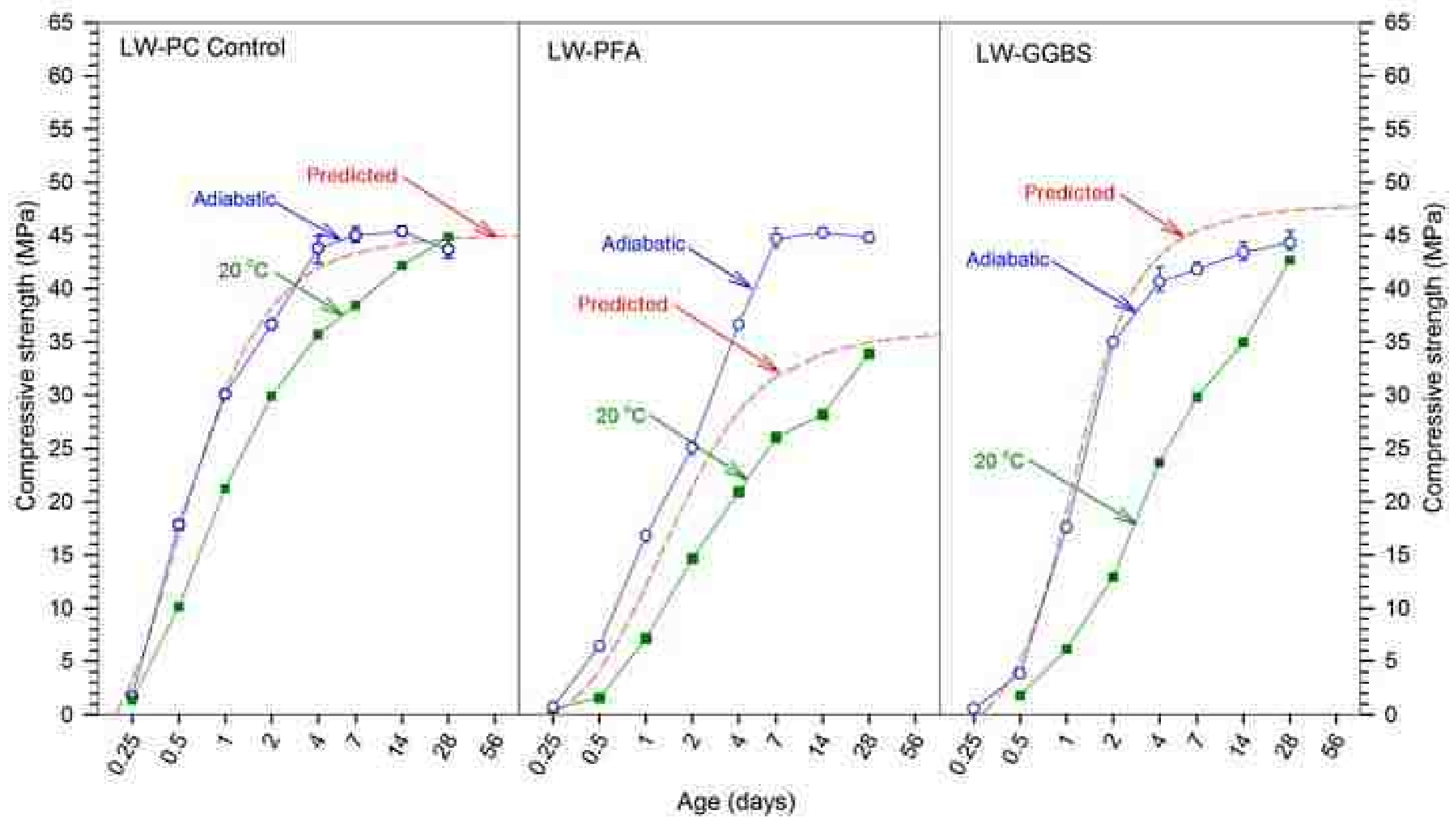




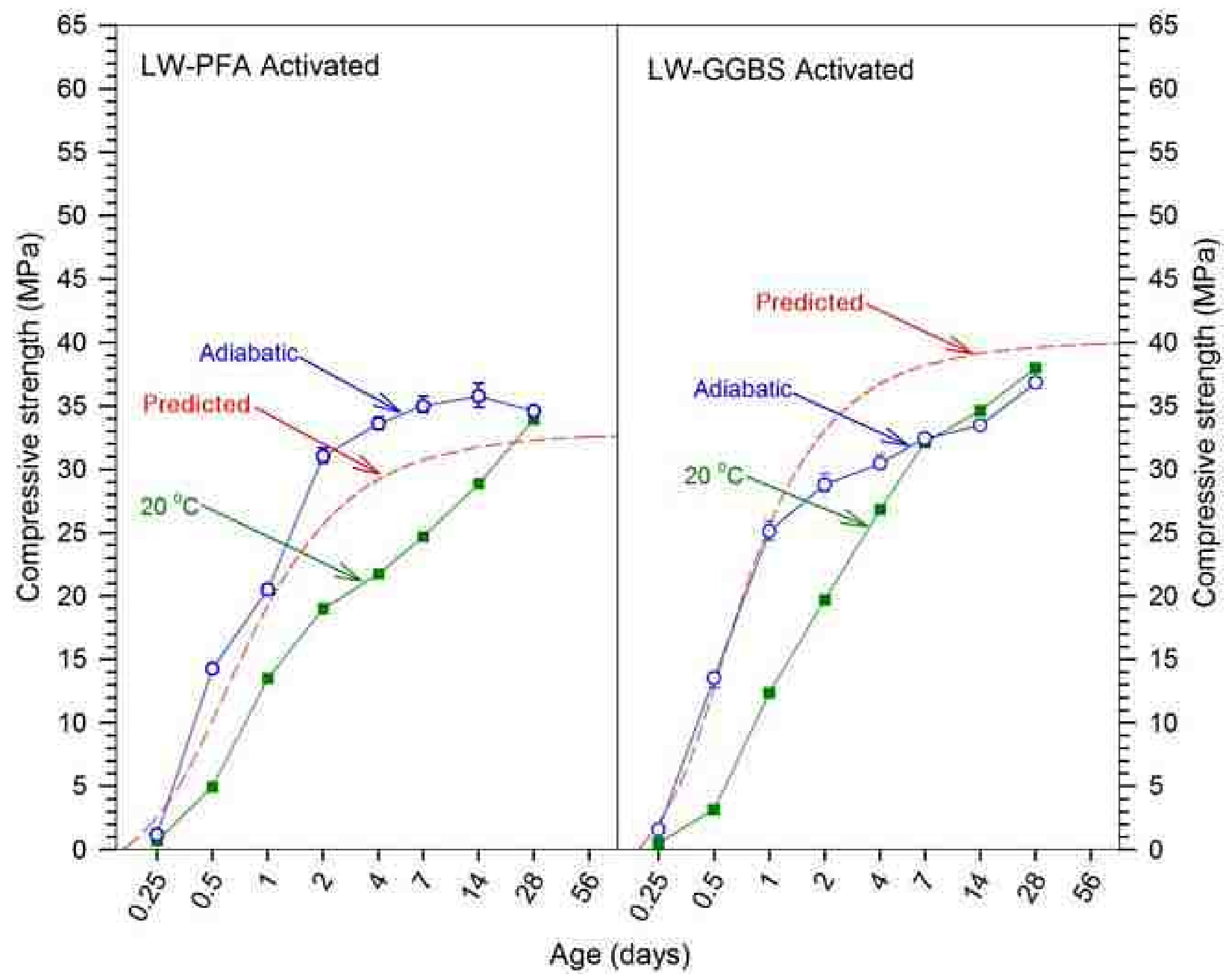




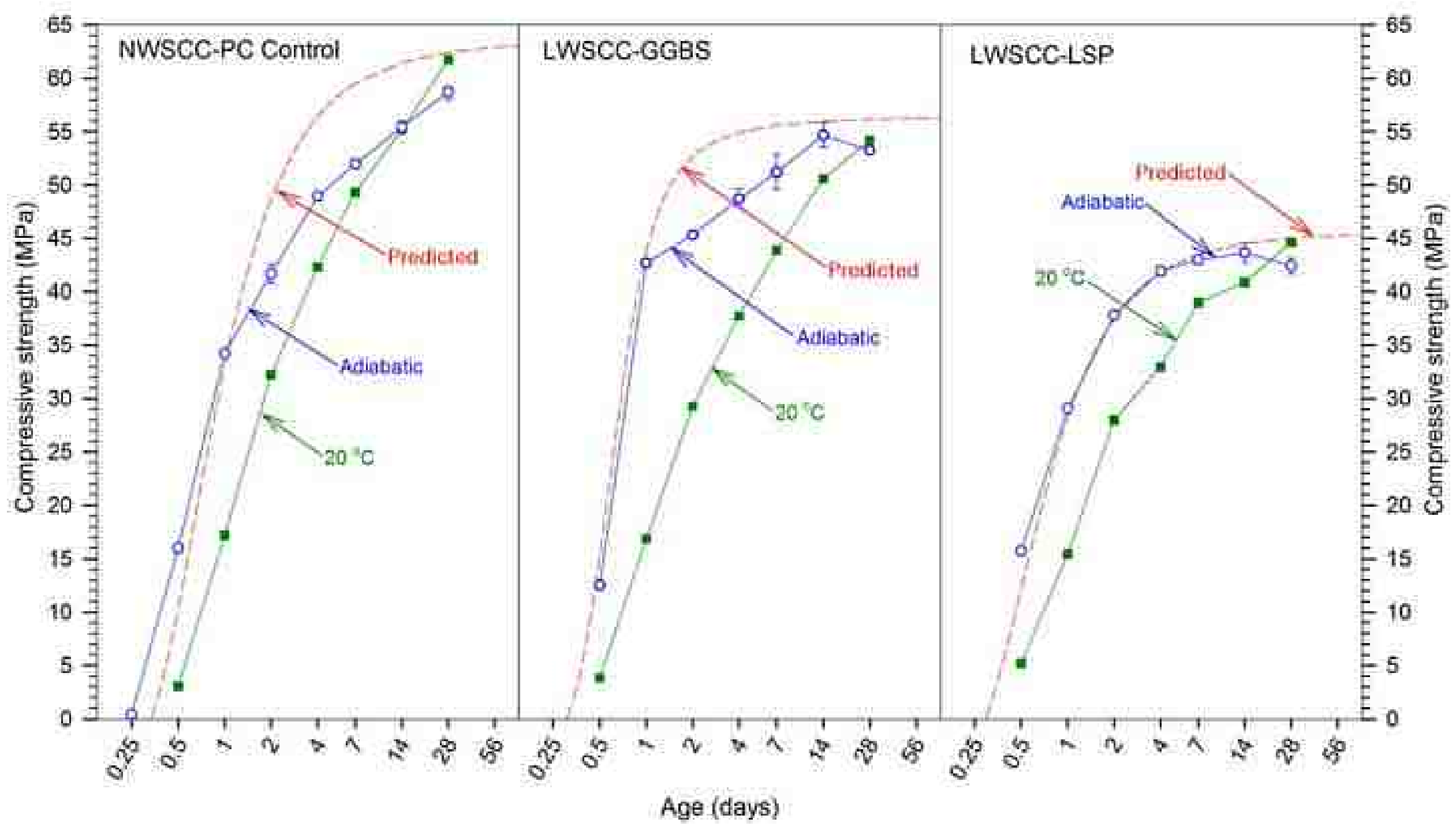

